\title{
Entre a paragem e o trânsito: Atenção Psicossocial para a
} errância e o nomadismo

\section{Between stop and transit: Psychosocial Attention to Wandering and Nomadism}

\author{
Cledione Jacinto de Freitas'1, José Sterza Justo²
}

\begin{abstract}
Resumo
O mundo atual produz mobilidades geográficas e psicossociais diversas. Dentre elas encontram-se aquelas realizadas por andarilhos e pessoas em situação de rua, que vivem em trânsito constante pelas rodovias ou habitam espaços abertos e públicos da cidade. O objetivo deste artigo é examinar e discutir políticas públicas e práticas na área da saúde mental coletiva e seus posicionamentos em relação às formas de vida nômades e errantes. Para tanto, foram analisados e comparados princípios e estratégias dos serviços públicos de saúde com o modo de vida de andarilhos e pessoas em situação de rua. Como principal conclusão, foi possível constatar que os serviços de atenção em saúde mental pública enfrentam dificuldades e obstáculos para acolher e contemplar as demandas dessas pessoas porque se orientam por estratégias e serviços calcados na perspectiva da territorialização e da vida sedentária situada em espaços geográficos e psicossociais fixos e estáveis.
\end{abstract}

Palavras-chave: Atenção Psicossocial. Errância. Nomadismo. Políticas públicas.

\begin{abstract}
The present world produces diverse geographic and psychosocial mobilities. Among them are those performed by wanderers and homeless people, who live in constant transit through highways or inhabit open and public spaces of the city. This article aims to examine and discuss public policies and practices in the field of collective mental health and their positioning in relation to nomadic and wandering life forms. For that, the principles and strategies of public health services were analyzed and compared with the way of life of wanderers and homeless people. As the main conclusion, it was possible to observe that public mental health services face difficulties and obstacles to accept and respond to the demands of these people because they are guided by strategies and services based on the perspective of territorialization and sedentary life in fixed and stable geographical and psychosocial spaces.
\end{abstract}

Key words: Psychosocial Attention. Wander. Nomadism. Public policy.

\footnotetext{
${ }^{1}$ Universidade Estadual Paulista: Campus Assis, Assis, SP, Brasil. E-mail: cledionefreitas@hotmail.com

${ }^{2}$ Universidade Estadual Paulista: Campus Assis, Assis, SP, Brasil. E-mail: sterzajusto@yahoo.com.br
} 


\section{Introdução}

Refletir sobre a Atenção Psicossocial no que concerne à errância e ao nomadismo é se debruçar sobre algo extremamente complexo e se defrontar com muitos paradoxos. Afinal, a mesma sociedade que incita a vida em movimento, em mudança constante, criando e estimulando desterritorializações e a habitação de não lugares (Augé, 2012) se mostra impotente para lidar com certas subjetivações das condições de intensa mobilidade geográfica e psicossocial e de transumâncias que ela mesma promove (Virilio,1996). As chamadas "populações em situação de rua" e os "trecheiros" ou os "andarilhos", ${ }^{3}$ que vivem transitando de cidade em cidade ou caminhando sem destino pelos acostamentos das rodovias, são casos típicos do paradoxo que se forma numa sociedade dromológica, isto é, numa sociedade presidida pela lógica da celeridade (Virilio, 1996) que, no entanto, pune, desqualifica ou negligencia certas formas de nomadismo ou de vida errante. São populações e indivíduos que escapam aos mecanismos usuais de controle e gestão da mobilidade geográfica, social e psicológica, passando a representar um problema ou até mesmo um perigo para a governabilidade das cineses constitutivas do mundo contemporâneo.

A conexão entre errância e vadiagem, mendicância, charlatanismo, vigarice, loucura, perigo, aventura descompromissada, dentre tantas outras conexões estigmatizantes, tem uma

\footnotetext{
3 Trecheiros são aqueles que vivem transitando de cidade em cidade, realizando pequenos bicos ou sobrevivendo da ajuda de entidades assistenciais ou, ainda, de "achaques" (pedidos de ajuda à população em geral). Andarilhos são aqueles que vivem
}

longa história, conforme aponta Geremek (1995), em seu estudo sobre essas figuras humanas retratadas pela literatura entre os séculos XV e XVII. Afirma ele que "na multiplicidade de significados desse termo [errante - vagabundo] apenas um elemento permanece constante: a mobilidade no espaço, a vida itinerante" (Geremek, 1995, p. 257). Na vida relativamente enclausurada da Idade Média e do início da modernidade disciplinada e ordeira, as movimentações humanas soavam como ameaçadoras e perigosas.

Conforme enfatiza Deleuze (1992, pp. 219-226), em contraste com modelos de vida enclausurada em espaços fechados e em segmentos de tempo bem delimitados e finitos, surgem, na atualidade, modelos de vida baseados em espaços abertos e em fluxos de tempo contínuo, produtores de subjetivações incessantes. Trata-se do advento da sociedade de controle que, diferentemente da sociedade disciplinar tão bem descrita por Foucault (2009), já não busca confinar a vida em espaços fechados, vigiá-la de perto e docilizar os corpos por meio de técnicas e instrumentos de adestramento próximos e concentrados nos espaços de confinamento, mas sim busca o controle por meio de tecnologias e sistemas ondulatórios, capazes de rastrear e monitorar corpos e subjetividades em movimento. A sociedade dos espaços abertos e do tempo contínuo, necessária para a maximização da produção e do consumo, no capitalismo tardio, precisa controlar os fluxos, a velocidade, os

caminhando pelos acostamentos das rodovias, carregando todos seus pertences num saco às costas ou em algum carrinho de mão improvisado. Dificilmente adentram as cidades. 
espaços e direções, reger itinerários, rotas e percursos na grande rede de conexão formada por territórios múltiplos e diversificados, interligados, pelos quais os indivíduos transitam.

A loucura e o sofrimento psíquico estão inseridos na mesma dromologia da sociedade de controle, isto é, são também expressões da produção de subjetividade resultante das condições de vida marcadas pelos paradoxos que se formam no confronto entre as incitações à mobilidade, por um lado, e por outro lado as estratégias de gestão e controle daquilo que foge aos sulcos e caminhos traçados para os percursos das subjetividades (Brazão, 2014; Danziato, 2010). Vale lembrar que, etimologicamente, a palavra delírio se remete à palavra grega de-liros, alusiva a tudo aquilo que fugia ou escapava aos sulcos escavados na terra para seu cultivo. Analogamente, podemos entender que a loucura ou o sofrimento psíquico, na atualidade, é o que resta ou escapa aos caminhos, rotas ou percursos sulcados na rede de relações psicossociais pelo trânsito das subjetividades normalizadas. O que foge ou salta fora dos sulcos escavados para o escoamento das produções subjetivas, pela racionalidade normativa, passa a ser objeto de estratégias especiais de controle. As produções de subjetividade que escapam aos dromocontroles usuais passam a ser objeto de atenção especial e de práticas que procuram redirecionar os fluxos e processos de subjetivação para as canalizações principais que estabelecem os caminhos e ritmos das caminhadas possíveis na rede de espaços psicossociais e de territórios existenciais múltiplos disponibilizados para o sujeito.

Cabe indagar até que ponto as políticas públicas e práticas atuais destinadas a cuidados no campo da saúde mental se articulam com as sofisticadas estratégias da sociedade de controle e se integram aos seus mecanismos de monitoramento das deambulações em espaço aberto que caracterizam a vida em trânsito na contemporaneidade (Justo, 2011a). É sabido o quanto os modelos manicomiais, forjados para a contenção da loucura, responderam à lógica da sociedade disciplinar. É, igualmente, sobejamente conhecida a estratégia, adotada até os fins do século XVI, de se livrar dos loucos e demais indesejados embarcando-os em quaisquer navios para rumarem sem destino (Foucault, 2003). Resta saber o quanto os atuais modelos de tratamento e atenção da loucura e do seu sucedâneo mais recente, o chamado "sofrimento psíquico”, se compõem com o recente movimento de substituição (ou complementação) da lógica disciplinar pela lógica de controle, monitorando as subjetivações desviantes, também elas desconfinadas e colocadas em espaço aberto, ou o quanto não aderem a essa lógica ou até se confrontam com ela assegurando possibilidades de subjetivação de-lirantes - fora dos liros - e errantes que, saltando da intricada rede de trilhos que interliga os diferentes territórios estabelecidos, possam criar outros caminhos possíveis e realizar outras conexões, além daquelas já sulcadas e previstas.

Este artigo se propõe a examinar e discutir as conexões das políticas públicas e de práticas na área da saúde mental coletiva com a lógica da sociedade de controle, tomando, particularmente, o caso de pessoas em situação de rua, andarilhos e trecheiros que podem ser situados no epicentro de um dos principais paradoxos da sociedade de controle: a forte 
incitação à mobilidade e, ao mesmo tempo, o intenso controle das movimentações para que não escapem aos rumos e possibilidades de deslocamento pelas redes, estabelecidas mediante dromopolíticas normativas que regem o trânsito psicossocial.

\section{Método}

Para atingir o objetivo proposto, foram compilados e analisados documentos oficiais (Leis instituindo políticas de atenção básica em saúde e políticas voltadas para inclusão da população em situação de rua; diretrizes normativas dos Caps e dos Consultórios na Rua, manuais de orientação do trabalho de técnicos da área da saúde com a população em situação de rua e outros documentos elaborados pelo Ministério da Saúde e pelo Ministério do Desenvolvimento Social). O corpus desta pesquisa abrangeu, ainda, artigos científicos, livros, teses e dissertações levantados na literatura especializada. Tanto os documentos oficiais quanto o material selecionado das fontes bibliográficas foram submetidos a uma análise de conteúdo, na vertente proposta por Bardin (2009). Todo o material coletado das fontes utilizadas passou por uma primeira leitura, orientada por categorias previamente estabelecidas, mediante a qual foram identificados e selecionados os conteúdos relacionados aos objetivos da pesquisa. Os conteúdos dos documentos oficiais e da literatura revisada referidos aos modos de vida de pessoas em situação de rua e, especialmente, de trecheiros e andarilhos, bem referidos às atenções, cuidados e tratamentos dispensados a eles pelos serviços públicos de saúde e de assistência social foram discutidos entre si e em suas relações com teorias que tratam das mobilidades psicossociais na contemporaneidade.

\section{Errância e errantes na atualidade}

A errância como um dos modos de subjetivação - talvez o mais radical - das incitações à mobilidade acaba por se constituir num problema, mesmo para a sociedade de controle, cujos mecanismos são incapazes de enquadrá-la nas trajetividades (subjetividades produzidas em trânsitos ou em trajetos), de acordo com Virilio (1993), ou nos fluxos de mobilidade normatizados. $\mathrm{O}$ errante propriamente dito não vai de um lugar a outro, se deslocando por espaços psicossociais posicionados em rede, como fazem trabalhadores, consumidores, usuários de serviços públicos ou privados prestados em diversas áreas, tais como de transporte, saúde, educação, lazer, cultura e tantas outras, mas sim se deslocam a esmo, ao sabor de contingências imediatas, transitando mais fora ou à beira do que dentro das rotas e vias de circulação estabelecidas. Maffesoli (2001), ao tratar da errância, a considera como fundadora e positiva, pois sem ela o novo não seria possível.

A fundação, à qual se refere o autor, é "pulsão da errância" que, segundo ele, foi a principal responsável pela constituição da humanidade ao impelir o homem, desde o início de sua história, a abandonar lugares estabelecidos e partir para outros, a aventurar-se pelo mundo, não somente em busca de melhores condições para viver, mas também pelo ímpeto de ir além, ultrapassar limites e fronteiras e experimentar o novo e o desconhecido. Maffesoli (2001) trata a 
errância, na atualidade, também como uma ruptura com as mordaças do trabalho e do produtivismo. Nesse sentido, a figura da vagabundagem - corrosiva para capitalismo e atentatória às estratégias disciplinares - associada a pessoas em situação de rua, andarilhos $\mathrm{e}$ trecheiros, funciona como uma forte desqualificação dessa forma de viver.

Portanto, o mais perigoso para a ordem social nem seria propriamente a improdutividade desses errantes, mas o sentido de liberdade que suas vidas expressam, o sentido de insurgência como aquele que brota da contestação ou ruptura com o trabalho, da forma como está estruturado no capitalismo. A radicalidade da ruptura da errância com a vida sedentária e disciplinada pode ser notada nos andarilhos, uma vez que eles escapam aos mecanismos de "dromocontrole" (Virilio, 1996) instituídos para modular movimentações e tráfegos de corpos, desejos, pensamentos, afetos e demais produções do sujeito. Por estarem fora das cidades e do alcance das redes de captura e controle, conseguem viver "sem eira nem beira", sem rumo, sem destino, fora dos lugares instituídos, diferentemente das pessoas em situação de rua que, limitadas aos espaços citadinos, estão expostas aos mecanismos de dromocontrole, assim como os trecheiros que transitam entre cidades e podem cair nas malhas de tais mecanismos. Justo (2012), acrescenta que esse movimento pode representar ameaça por ser construído e constituído bem diverso do instituído e configurar um novo modo de produção de circulação, mais autônomo e independente.

O movimento é constituinte deles, que fazem do caminhar sua ação e sua resistência e lhes dá o significado existencial, como também, uma saída subjetiva e um modo de se mover no espaço-tempo. A relação espaço-tempo, para Justo (2011b), vivenciados pelos trecheiros e andarilhos, é de outra natureza. Estão no trecho, um espaço e tempo do movimento, da dromologia. $\mathrm{O}$ mundo hipercinético e incitador à mobilidade torna todos, de certa forma, deambulantes e passageiros, à feição dos trecheiros e andarilhos, se desprendendo de lugares e territórios estáveis e fixos, porém, realizando deslocamentos controlados, regrados e administrados, tais como são tipicamente os deslocamentos dos turistas monitorados por agentes de viagens. $\mathrm{O}$ viajante realiza percursos ou deslocamentos espaço-temporais administrados, intermediados por tecnologias e saberes especializados que o tornam, muitas vezes, um mero passageiro e espectador das paisagens que desfilam diante de seus olhos. Nessa via, ocorre uma diferença no modo de experienciar e viver a mobilidade entre andarilhos e trecheiros e os demais, conforme Justo (2011a), que é o sentido de ruptura com todas as formas de sedentarismo e de dromocontroles, assumindo um caráter eminentemente errante. É a radicalidade da ruptura com os vínculos e lugares de assentamento psicossocial (família, trabalho, casa, etc.) e a perambulação constante e sem destino.

Kasper (2006), nessa direção, em sua pesquisa com pessoas em situação de rua, destaca o sentido de ruptura desse modo de vida com os assentamentos e sedentarizações que marcam a vida convencional dos citadinos que gravita, sobretudo, em torno do tripé formado por uma residência fixa (casa), família e trabalho. Viver na 
rua, segundo depoimentos coletados, produz um sentimento de liberdade que se estende para além de uma moradia, de uma família nuclear e um trabalho opressivos e abrange a produção de um território existencial efêmero, em constante recomposição, povoado de objetos ressignificados e refuncionalizados em uma recomposição subjetiva produzida na construção de modos de habitar a rua.

Trata-se, portanto, de formas de vida (produzidas por andarilhos, trecheiros e pessoas em situação de rua) bem diferentes das formas sedentárias ou mesmo das formas nômades administradas e domesticadas pelos refinados mecanismos e tecnologias de dromocontrole da atualidade. A ruptura ou distanciamento da normatividade sedentária ou do nomadismo controlado e administrado traz a contrapartida das dificuldades, obstáculos e sofrimentos para levar adiante uma vida desgarrada ou equidistante de epicentros da lógica da sociedade de controle ou dos resquícios da sociedade disciplinar. $\mathrm{Na}$ concretude das experiências de vida errante dos andarilhos, trecheiros e mesmo das pessoas em situação de rua não são raros os casos de extremo sofrimento, porém, nada diferente do que também se passa em outras formas de vida, inclusive aquelas bastante aderidas aos sistemas peritos de gestão da vida sedentária ou nômade. O grande equívoco é patologizar o modo de vida errante, considerando-o como uma doença, um transtorno ou um desvio a ser curado, corrigido ou evitado. A Psiquiatria tradicional até cunhou um diagnóstico para patologizar a errância: dromomania. A pretensão de promover saúde ou de reduzir vivências de sofrimento nessa forma de vida tem que, fundamentalmente, respeitá-la e admiti-la como uma das possibilidades de se viver e não como mais uma patologia a ser erradicada.

\section{A errância nas políticas públicas e nos modelos atuais de atenção à saúde mental coletiva}

O arcabouço da Atenção Psicossocial perpassa por acontecimentos, principalmente no campo da Saúde e da Assistência Social, inspirados e motivados por vários movimentos sociais, políticos, culturais e institucionais, produzindo tensões, embates, concessões, resistências e novos modos de cuidado. Nesse complexo de interações, foram construídas políticas de atenção e cuidados para pessoas em sofrimento psíquico. O movimento da Atenção Psicossocial, conforme Yasui, Luzio e Amarante (2018) e Amarante (2007), foi constituído a partir da reforma psiquiátrica, do movimento antimanicomial e da luta por garantia de direitos às pessoas em sofrimento psíquico. A Constituição de 1988 foi fundamental ao elevar a saúde e assistência social à categoria de direitos, imputando ao Estado a responsabilidade para assegurá-los a todos os cidadãos. O direito ao acesso aos serviços de saúde foi estabelecido pela Lei $n^{\circ} 8.080$, de 1990, que criou o Sistema Único de Saúde (SUS), e a Lei no 8.142, de 1990, que instituiu a participação popular na sua gestão, pela Lei $n^{\circ}$ 10.216, de 2001, que dispõe sobre direitos e proteção a pessoas em sofrimento psíquico e redimensiona o modelo de assistência à saúde mental e a Política Nacional da Atenção Básica de 2006 e de 2012. O direito à Assistência Social e suas conexões foram estabelecidos, inicialmente, pela Lei $n^{\circ}$ 8.742, de 1993, que criou a Lei 
Orgânica de Assistência Social, outras legislações posteriores complementaram as iniciais e deram mais organicidade e força à assistência social como um todo e a suas interfaces com a saúde. Entre elas se destacam: a Política Nacional de Assistência Social (PNAS) de 2004 e a Norma Operacional Básica (NOB/Suas) de 2005, que institui o Sistema Único de Assistência Social; a Resolução $\mathrm{n}^{\circ}$ 109, de 2009, que estabelece a Tipificação Nacional dos Serviços Socioassistenciais no Suas, os Serviços Especializados de Abordagem Social e a Portaria n 3.088, de 2011, que institui a Rede de Atenção Psicossocial (Raps).

A Rede de Atenção Psicossocial, segundo Brasil (2011b), é constituída por seis componentes. $\mathrm{Na}$ atenção básica, estão a Unidade Básica de Saúde e equipe de atenção básica para populações específicas: equipe de consultório na rua; equipe de apoio aos serviços de Atenção Residencial de Caráter Transitório e centros de convivência; atenção psicossocial especializada composta pelos Centros de Atenção Psicossocial em suas diversas modalidades; Atendimento de Urgência e Emergência formada por Samu, Sala de Estabilização, UPA, portas hospitalares de atenção a urgência/pronto-socorro, Unidades Básicas de Saúde, etc.; atenção residencial de caráter transitório: Unidade de Recolhimento e Serviços de Atenção em Regime Residencial; Atenção Hospitalar formada por enfermaria especializada em hospital geral e serviço hospitalar de referência para atenção às pessoas em sofrimento psíquico ou necessidades decorrentes de uso de álcool e outras drogas; estratégias de desinstitucionalização com os
Serviços Residenciais Terapêuticos e a Reabilitação Social.

Concernente à atenção prestada às pessoas em situação de rua, o Ministério da Saúde, nos últimos anos, envidou esforços para atender ao disposto na Política Nacional para Inclusão Social da População em Situação de Rua, criando dispositivos, estratégias para a atuação, tanto no tocante à atenção em saúde geral, quanto na saúde mental. Dentre eles podemos destacar o Plano Operativo para Implementação de Ações em Saúde da População em Situação de Rua 20122015 (Brasil, 2012a); o Manual Sobre o Cuidado à Saúde Junto à População em Situação de Rua (Brasil, 2012b); a Política Nacional da Atenção Básica (Brasil, 2012d), que revisa as normas para a organização da Atenção Básica; o Consultório de Rua do SUS (Brasil, 2010) e a Portaria no 122, de 25 de janeiro de 2012, que define as diretrizes de organização e funcionamento das Equipes de Consultório na Rua (Brasil, 2012c).

A rede de atenção às pessoas em situação de rua, na saúde, consiste basicamente nos Consultórios na Rua, nos Caps, em suas diversas modalidades, na Estratégia Saúde da Família (ESF) e no Núcleo de Atenção à Saúde da Família (Nasf). $\mathrm{Na}$ Assistência Social, a rede inclui o Centro de Referência de Assistência Social (Creas), o Centro de Referência Especializado para População de Rua (Centro Pop) e serviços, tais como o Serviço de Proteção e Atendimento Especializado a Famílias e Indivíduos (Paefi), o Serviço Especializado de Abordagem Social e equipamentos complementares, tais como Albergues e Casas de Passagens. No que concerne às outras políticas públicas, relativamente à construção da rede de atenção à errância e ao 
nomadismo, ainda são insignificantes ou inexistentes. Esses dispositivos e estratégias previstos na legislação e nas ações de governo estão direcionados às pessoas em situação de rua circunscritos aos limites das cidades, com atenção preferencial para os grandes centros, como pode ser observado na nova política, que tem a rua como lócus da atenção, com objetivo de atuar diretamente no território, nos espaços abertos, na rua, com cuidado especial para as pessoas que fazem uso de substâncias psicoativas e estabelece um número mínimo de 80 pessoas em situação de rua para sua implantação (Brasil, 2012b).

Embora existam modelos e práticas diferentes no campo da Saúde Mental Coletiva, tomaremos como referência o modelo da Atenção Psicossocial por ser mais recente e ter surgido no bojo do advento da sociedade de controle. Portanto, trata-se de um modelo que acompanhou o esgotamento do modelo confinador da sociedade disciplinar, calcado nos manicômios, e o advento da tendência de substituição (ou complementação) dos espaços fechados pelos espaços abertos que possibilitou a criação de políticas e serviços, na área da saúde mental, descentrados e implementados em rede, articulando diversas áreas de saber, espaços psicossociais e práticas profissionais.

Atenção Psicossocial constitui um processo social complexo, em que ocorrem, a um só tempo e articuladamente, transformações nos campos: teórico-conceitual, técnico assistencial, político-jurídico e sociocultural e, portanto, se inscreve como um processo de transição paradigmática da Psiquiatria. Como um processo de transição paradigmática complexo, "não se restringe à reestruturação técnica, de serviços, de novas e modernas terapias: torna-se um processo complexo de recolocar o problema, de reconstruir saberes e práticas, de estabelecer novas relações” (Amarante, 2009, p. 1). Portanto, a Atenção Psicossocial procura superar o modelo psiquiátrico por meio do qual a loucura foi apropriada pelo discurso médico como alienação, degeneração ou doença mental, associada à anormalidade e à periculosidade. Busca desconstruir a relação doença-cura, cujo tratamento supõe o isolamento, a tutela e a desqualificação do sujeito considerado doente mental, bem como inventar" novas possibilidades de inscrição dos sujeitos no corpo social" (Amarante, 1996, p. 110). Enfim, na Atenção Psicossocial, o cuidado ocorre nos espaços sociais, por intermédio de uma multiplicidade de ações, de modo a propiciar o reposicionamento do indivíduo, tomado em sua dimensão subjetiva e sociocultural, tornando-o um ator social e sujeito de direitos.

No campo da assistência aos usuários dos serviços de saúde, as propostas da Atenção Psicossocial, segundo aponta Amarante (1996), têm propiciado a construção de uma rede de ações sustentada em espaços de sociabilidade, de trocas, em que se enfatiza a produção de saúde como produção de subjetividades. Ou seja, temse buscado colocar a doença entre parênteses e entrar em contato com o sujeito, e assim romper com as práticas disciplinares; aumentar a possibilidade de recuperação do seu estatuto de sujeito de direitos. Além disso, observa-se transformações tanto na concepção dos novos serviços, como agilizar e democratizar a sua forma de organização e gestão, bem como procuram desenvolver experiências no território. 
Pensando na atenção à saúde, é possível realizar uma Atenção Psicossocial em trânsito, nômade ou errante? Essa talvez seja a pergunta a ser respondida para que se possa abarcar as pessoas em situação de rua, trecheiros e andarilhos na Atenção Psicossocial. No entanto, abrir-se para tal possibilidade pode implicar mudanças em pilares dos serviços que nem são tão visíveis, como é o caso do pilar do sedentarismo familial ou grupal. O desafio maior é abdicar da ideologia sedentarizadora e territorializante fortemente cravada nas políticas públicas, não só no campo da saúde como também no da assistência social e educação, que orienta práticas de inscrição do usuário num determinado território ou área de abrangência do serviço por meio, sobretudo, da tentativa de estreitar laços com a família, com o trabalho/emprego que possa gerar renda e garantir a fixação do sujeito em detrimento de relacionamentos e formas de trabalho capazes de assimilarem o imprevisto, o movimento e o desenraizamento, típicos da vida em trânsito.

Adotar uma postura de aceitação da vida errante, não assentada num determinado território ou foragida dos trânsitos instituídos por caminhos pavimentados entre territórios interligados por redes, exige uma mudança significativa nos modos de encarar o que foge ao normativo, ao que é estabelecido como ideal, sobretudo no que diz respeito à constituição de vínculos e de relacionamentos estáveis e duradouros.

A errância e o nomadismo ainda estão muito longe de serem assimilados pelas políticas de Assistência Social e de Saúde, que são as duas políticas que procuram contemplar essa população, ainda que investidas, paradoxalmente, da ideologia sedentarizadora. A Política de Assistência Social era, até pouco tempo, a única política que procurava contemplar, em seus programas, pessoas em situação de rua, trecheiros, andarilhos e itinerantes. Hoje, essa população é enquadrada nos serviços de Proteção Social Especial disponibilizados nos Creas e nos Centros Pop, na Tipificação dos Serviços Socioassistenciais, no Paefi e no Serviço Especializado de Abordagem Social responsável pela atenção no território às pessoas itinerantes. Após 2008, passou a ser enquadrada também nos serviços criados nas políticas de saúde na área da atenção básica em Saúde Mental, nos Caps, na Estratégia Saúde da Família (ESF) e nos Consultórios na Rua, atuando de maneira integrada e articulada na proposta da intersetorialidade.

Não foi somente a Assistência Social a responsável por chamar a atenção para os errantes e nômades e procurar enquadrá-los nos modos de vida estacionários-territorializados, pautados na lógica e na ideologia sedentarizantes. Antes mesmo da criação de políticas específicas governamentais, as Igrejas e as Instituições Filantrópicas disponibilizavam algum tipo de ajuda imediata, tal como comida, roupas, albergue e outros auxilios de cunho caritativo para a sobrevivência ou para orientação religiosa e espiritual, que sempre incluíam a valorização dos vínculos com a família, fosse pelo entendimento de que essas "ovelhas desgarradas do rebanho" poderiam ser resgatadas ou de que tinham que passar por essa provação (Nascimento, 2012).

A Política Nacional para Inclusão Social da População em Situação de Rua (Brasil, 2008) 
representa uma grande investida do Estado na realidade dessa população com o objetivo primordial de inseri-la ou reinseri-la, de incluí-la socialmente, mediante programas e ações de vários ministérios, como o Ministério das Cidades, o Ministério da Educação, Ministério da Cultura, Ministério do Trabalho e Emprego, Ministério da Justiça e a Secretaria Especial de Direitos Humanos. Nessa iniciativa é visível o descaso ou negligência com a situação dos trecheiros e andarilhos, contemplados com algum tipo de serviço ou assistência somente quando são somados às pessoas em situação de rua. As poucas e restritas políticas de atenção existentes estão circunscritas ao espaço citadino, praças e ruas, podendo alcançar alguns trecheiros que passam por esses espaços, mas jamais alcançam aqueles andarilhos que raramente adentram as cidades e vivem, sempre, perambulando pelos acostamentos das rodovias. O descaso com andarilhos e trecheiros, que vivem perambulando pelos acostamentos das rodovias, expressa bem a radical negação dessa forma de existência. A negação e o rechaço a essa forma de vida são tão intensos que impedem até mesmo o reconhecimento de sua existência no cenário social. As políticas públicas de saúde, mesmo aquelas assentadas no paradigma da atenção psicossocial, não escapam às dificuldades e negligências em relação aos errantes, sobretudo andarilhos e trecheiros.

A forte presença da imagem do pé, representa metonimicamente as pessoas em situação de rua. Como representação da pessoa em situação de rua no seu todo, o pé aparece frequentemente em documentos estatais orientadores das políticas públicas e também na mídia, ao veicular alguma notícia sobre essa população. Até o Ministério da Saúde (Brasil, 2012b) evidenciou os pés dessas pessoas, ao elaborar uma cartilha de orientação para cuidados básicos aos moradores de rua. Nela, os problemas que acometem os pés, dentre os problemas clínicos tidos como característicos da população de rua, aparecem em primeiro lugar. Mais que qualquer parte do corpo, os pés são objetos precípuos de identificação dessa população, configurando, por assim dizer, o modus operandi de constituição subjetiva, conforme destaca Frangella (2004), pois é pelo caminhar que constroem trajetos; é pelos pés que se movem no espaço-tempo e que se afirmam na dromologia.

No tocante à errância, ao nomadismo e sua relação com a Atenção Psicossocial, Albuquerque (2009) e Borysow e Furtado (2014) tratam da dificuldade de atendimento, pelos Caps, das pessoas em sofrimento psíquico, por não terem endereço fixo. Por esse motivo, os gestores argumentavam que os errantes de rua não faziam parte da área de abrangência dos serviços que coordenavam ou que eram de responsabilidade da Secretaria de Assistência Social. A alternativa para o atendimento, pelos Caps, foi colocando-os em endereços fixos; foi referenciá-los no território para, então, realizar o atendimento, utilizando preferencialmente albergues como local de assentamento e ponto de referência para o cuidado. Os referidos autores sustentam haver uma dificuldade de articulação da rede, ficando a atenção baseada na iniciativa de algum profissional ou da Assistência Social.

A política de saúde, na atenção básica, conforme Brasil (2012), organiza os serviços e o cuidado sob o primado do território, visto como 
o lócus de atenção e atuação com a população adstrita em uma determinada área, pela responsabilização e humanização. Domicílio, família e quarteirões, e não propriamente as ruas, são as bases e eixos organizadores das políticas e dos serviços. Nota-se uma preocupação sistemática das políticas de atenção à saúde, no caso da Atenção Psicossocial, para com as pessoas em situação de rua, a saber, um público heterogêneo, composto por pessoas desempregadas, imigrantes, egressos do sistema prisional e psiquiátrico, etc. (Brasil, 2008), utilizando os espaços urbanos de várias maneiras, seja fixando-se em algum ponto, seja estando em processo de itinerância entre praças ou bairros, seja sendo deslocados e expulsos. A rua configura-se como espaço subjetivo, como habitat, dificilmente estão em trânsito, o que pode caracterizar uma situação de "semissedentarismo" por terem, predominantemente, assentamentos em ruas, praças, espaços públicos e instituições. Já os trecheiros e andarilhos não são citados, talvez pelo fato de, primeiro, não se enquadrarem direito na categoria das pessoas em situação de rua fazem das cidades, ruas e rodovias espaços de trânsito, de passagem e, por isso mesmo, são errantes; segundo, porque tais políticas são eminentemente citadinas, referenciadas em espaços de parada, definíveis, racionalizados e sedentarizantes.

Um dos maiores entraves para se ter uma política de atenção e cuidados aos errantes, seja na área da Assistência Social, da Saúde, da Atenção Psicossocial, seja outra qualquer, consiste justamente em abdicar dos modelos institucionalizantes baseados em espaços fixos e estáveis, ainda que inseridos em redes, que acabam por manter o antigo caráter de reclusão e confinamento que persistem desde o início da Modernidade ou, como bem pontua Foucault (2003), desde o Surgimento dos Estados Modernos, em que os loucos, mendigos, leprosos eram confinados para "tratamento" (Foucault, 2010).

\section{Desafios da errância e do nomadismo para as políticas públicas e serviços de atenção psicossocial}

A errância dos trecheiros e andarilhos, trazendo em seu bojo o incerto, o imprevisto, o efêmero, a subversão da racionalidade estabelecida, a desterritorialização torna difícil sua domesticação e aderência a estratégias de cuidado baseadas em espaços fechados, em movimentações por redes de serviços preestabelecidas e em unidades de tempo sequenciais que asseguram a continuidade das ações assistenciais ou terapêuticas. Outro grande desafio para os cuidados dirigidos a trecheiros decorre da forte presença entre eles do consumo excessivo de bebidas alcoólicas e, em menor proporção, de outras drogas. Consumo que, na maioria dos casos, conforme Nascimento e Justo (2000), desenvolve uma extrema dependência que potencializa ainda mais relacionamentos e vínculos mínimos (tênues e efêmeros) necessários para a satisfação de necessidades básicas e para o acesso à bebida, via de regra, justificado como recurso para se afugentar o frio ou para se enfrentar outras adversidades. Em relação ao uso, abuso ou não de álcool e outras drogas pelas pessoas em situação de rua, Varanda (2009) apresenta resultados que apontam nessa direção, 
acrescentando que elas podem atuar na mediação das relações sociais e de sobrevivência nas ruas, bem como meio para alívio do sofrimento psíquico.

Tendo em vista que o uso de bebidas alcoólicas está bastante encrustado no modo de vida errante de pessoas em situação de rua e trecheiros, e que a atenção dispensada aos adictos, tanto na Atenção Básica, quanto na Saúde Mental, ainda é essencialmente centrada no Modelo Biomédico, tal como aponta Yasui, Luzio e Amarante (2018) e Amarante (2007), de caráter medicamentoso, acaba se aprofundando o fosso entre um modo de vida baseado na mobilidade e práticas de cuidado que exigem confinamento e estagnação. Além do álcool, podemos considerar a mania deambulatória ou a dromomania como saída subjetiva para muitas pessoas, principalmente para os andarilhos que tomam o caminhar como principal sentido de suas existências.

Contrariamente aos sedentários que temem e se angustiam com a possibilidade de uma vida errante, os andarilhos vivem as paradas e estacionamentos como fonte de sofrimento, ou seja, para eles a sedentarização se torna uma condição que produz adoecimento/sofrimento. Certa vez um andarilho que caminhava por um acostamento, mancando e usando uma bengala, ao ser indagado se sua perna doía quando caminhava, respondeu que não e completou: "quando ando não, quando paro é que dói” (Julião, 2013 , p. 37). Nesse caso, ele estava se referindo a uma dor física, mas diversos outros andarilhos dizem a mesma coisa, porém se referindo ao sofrimento psíquico que lhes acomete quando são obrigados a permanecer parados ou fixos em algum lugar, por exemplo, em situações de internamento para um tratamento de saúde, em períodos de frio muito intenso ou mesmo quando, eventualmente, arranjam algum bico de trabalho prolongado em propriedades rurais.

Para Justo (2011b), no caso dos andarilhos delirantes, a busca de apaziguamento de suas angústias, na errância, é bastante observável e acaba por denunciar os sofrimentos produzidos pela vida sedentarizante.

andar, perambular, deslocar pelas estradas, rodovias e cidades criam, nos andarilhos e trecheiros, espaços e territórios, tanto físicos quanto psíquico e existenciais diferentes dos produzidos pelos sedentários, forjando racionalidades, fugas, escapes e territorialidades em espaços abertos, num constante desenrolar de acontecimentos vividos no aqui e agora. Esse viver a esmo, errante, sem eira nem beira, não é assimilável pela nossa sociedade, mesmo sendo ela uma sociedade dromológica, isto é, calcada no movimento. Isso porque a errância propriamente dita, essa vivida por andarilhos, trecheiros, representa para os dromopoderes constituídos algo que the escapa e que foge às cinesias normalizadas, domesticadas e colocadas a serviço das forças e interesses hegemônicos que arrebatam o comando do funcionamento da sociedade.

Por produzir justamente o inesperado, o imprevisível e o desconhecido, Justo (2011a, 2011b) afirma que a errância traz em si, para os sedentários, medos e fantasias de não conseguirem lidar com a desordem e o caos do contato com o imprevisto, bem como de não conseguirem saírem ilesos do encontro com o desconhecido. Por isso, errar, aos olhos de um 
sedentário, torna-se anormal, perigoso e indesejável; é visto como signo de erro, de um desacerto da vida; como um desarranjo ou descaminho da trajetória de vida que configura um desvio maléfico fadado a intensos sofrimentos ou à perda da razão.

Loucura/sofrimento e errância são irmanados pela lógica normalizadora que se utiliza da discriminação dos desviantes, acompanhada de sua desqualificação e condenação, para valorizar aquilo que estabelece como sendo o tipo de subjetividade adequada e saudável. Tal lógica é tão disseminada e enraizada na cultura que se impõe como verdade inquestionável e insuspeita, como se pode observar no em uma matéria sobre moradores de rua publicada num jornal (Costa 2013), quando o autor atesta ser a melhor alternativa para o cuidado com as pessoas em situação de rua a internação compulsória, referendada pelo médico. Para o autor, primeiro, a rua não é um habitat possível; segundo, que só vai para a rua quem tem algum transtorno mental; terceiro, são eles mesmos os únicos responsáveis por irem para as ruas e, não menos importante, essas pessoas são desprovidas de razões para viver, por esse motivo, o Estado deve atuar no sentido de retorná-los para a casa, o trabalho e a família. Conforme a clarividência do articulista, "Dentro de uma normalidade ninguém trocaria um cobertor quente e cheiroso pelo frio enrolado num 'molambo'[...]" (Costa, 2013, p. 2). Com esses argumentos, defende a internação compulsória como o meio mais eficaz de solucionar esse "problema" que assola a sociedade.

À primeira vista, esse seria apenas um artigo de um morador indignado com a presença de pessoas nas ruas, seja perambulando, habitando ou usando álcool e outras drogas, principalmente nos locais denominados como “cracolândias". No entanto, esse artigo expressa algo mais abrangente, expressa o desejo, de grande parte da população, de limpeza e assepsia da cidade, significando isso retirar dela tudo o que representa impureza e diferença incômoda. No fundo, como acentua Bauman (1998), trata-se de anular os estranhos. Um dos motivos das tentativas de se anular os estranhos consiste justamente em um atributo que Bauman (1998), baseando-se em Sartre, denomina de viscosidade. Assim como o líquido viscoso adere à pele e não se solta com facilidade, os estranhos também não são anulados com facilidade, estão sempre presentes, "grudando" em nossas vidas e sujando nossa pele. A viscosidade produz também o temor da mistura, da perda da ordem e por esse motivo é combatida, pois "Cada um é 'viscoso' para o outro; mas cada um combate a viscosidade do outro em nome da sua própria pureza" (Bauman, 1998, p. 42).

As pessoas em situação de rua são vistas como duplamente viscosas: são portadoras da viscosidade da loucura e da viscosidade do nomadismo. Andarilhos e trecheiros são menos temidos quanto à viscosidade porque vivem a certa distância e são pouco visíveis, porém, o grude que eles denunciam nos sedentários, de forma radical, é a presença neles, ainda que dissimulada e mantida sob forte controle, do desejo de abandonar tudo, de se desfazer das amarras da sedentarização ou da mobilidade monitorada e "sair para o mundo".

A dificuldade e o desafio de se construir uma Atenção Psicossocial para as pessoas em 
situação de rua, andarilhos e trecheiros é admitir o nomadismo e a errância como uma das tantas possibilidades de se viver. A grande empreita é afastar o temor da viscosidade da loucura e da errância e trazê-las para o cotidiano da cidade, significando isso colocá-las próximas aos citadinos comuns, dando-lhes a possibilidade de conviver com a viscosidade da errância sentida como comichão de se perder no caos e descontrole da mobilidade geográfica, social, afetiva e cognitiva. Inversamente, tal proximidade também daria aos errantes a possibilidade de aproximação e contato com formas sedentárias de vida sem que, no entanto, se sentissem obrigados a retornarem a elas.

Os modelos atuais de atenção à saúde mental, em grande medida, até conseguiram bastante sucesso nas tentativas de se livrarem das estratégias biomédicas e medicamentosas que procuravam resolver o problema da viscosidade da loucura tentando contê-la com uso de psicofármacos e com o confinamento do louco em espaços fechados e isolados dos demais espaços sociais. De certa forma, os modelos atuais, no que concerne à espacialização do louco e da loucura, substituíram as fronteiras dos manicômios pelas fronteiras da família, dos Caps, dos serviços complementares ao tratamento psiquiátrico e psicoterápico, bem como dos Consultórios na Rua, ofertando cuidado nas ruas dos territórios. É fato que alargaram bastante os espaços de vida do usuário, mas não abdicaram da sedentarização, na medida em que vislumbram alguma possibilidade de alívio para o sofrimento psíquico, precipuamente, em situações de fixação, permanência e estabilidade, exatamente ao contrário da maneira de viver da população de rua, dos andarilhos e dos trecheiros.

No que concerne à errância, das pessoas que estão constantemente se deslocando de cidade em cidade ou pelas rodovias do país, a problemática se torna ainda mais premente, visto que ela sequer é objeto de atenção pelas políticas públicas, e quando há alguma atuação a tentativa é sempre de refreá-la, por não se admitir outros modos de vida que não aqueles inspirados no sedentarismo. No mínimo, se procura monitorar as movimentações dos errantes e modular sua velocidade e direção, pois não se admite um viver a esmo que possa escapar aos refinados controles e gestões das subjetividades.

Tais redes de monitoramento e de captura, calcadas na lógica de modulação da velocidade e de enquadramento da mobilidade em corredores de circulação, tentam recolocar os desviantes nas rotas e nos ritmos estabelecidos nas diversas esferas da vida. $\mathrm{Na}$ sociedade do dromocontrole, todo deslocamento é rigorosamente realizado pelos saberes especializados, tornando o transeunte um mero passageiro e não um protagonista de sua própria viagem, conforme enfatiza Augé (2012). Nesse sentido, os usuários dos serviços de saúde mental são postos em movimento por meio de deslocamentos na rede de atenção constituída por diversas práticas de cuidado e saberes e aí transitam como passageiros conduzidos por profissionais especializados. A rede permite algumas rotas, implementadas em nome de uma atenção singularizada ou individualizada, mas não permite que o usuário faça seu próprio percurso e, principalmente, que possa saltar fora dos circuitos possíveis e viver como um errante. 
A errância e o nomadismo, por resistirem às políticas sedentarizantes e de dromocontrole, representam um grande desafio para as políticas públicas de assistência, sejam no campo da assistência social, seja da saúde mental. Embora não sejam muitos os que vivem de maneira errante e avessa ao sedentarismo e aos dromocontroles, tais políticas para Yasui, Luzio e Amarante (2018), no tocante à Atenção Psicossocial, se não forem produzidas como modos de resistência, potencializadoras de modos de existir e de reposicionamento subjetivo, podem acabar por reproduzirem modos de vida pasteurizados e hegemônicos e caírem na lógica biomédica da captura e da domesticação. Acrescenta-se, ainda, parafraseando Lancetti (2008), a coexistência de dois modelos em tensão, no campo das políticas de saúde: um voltado para a contenção, para o instituído, calcado no modelo biomédico, e outro voltado para a continência, para o instituinte, para o cuidado coletivo e respeito à pluralidade da vida.

A ameaça ou o incômodo maior que representam moradores de rua, trecheiros, andarilhos e outros errantes parece derivar não do seu montante, como um segmento da população, mas da ruptura com padrões de normatividade calcados no sedentarismo disciplinar e nos dromocontroles que regem e gerenciam a mobilidade geográfica e psicossocial. Vale dizer, ameaçam, incomodam e se tornam indesejáveis não por sua relevância quantitativa, mas sim por sua relevância qualitativa, qual seja, por trazerem à tona a possibilidade de se poder escapar, de resistir a toda parafernália criada para modular a vida. Por isso mesmo, precisam ser contidos ou retirados da cena pública mediante ações de encapsulamento pelos serviços de assistência social ou de saúde mental que consigam, no mínimo, exercer algum monitoramento sobre seus deslocamentos.

Talvez o mais perturbador para a construção de uma Atenção Psicossocial seja o fato de a errância representar a deserção de modos de vida tão venerados e solidificados e sinalizar a possibilidade de criação de espaços subjetivos existenciais que se espojam na mobilidade espaço-temporal, na desterritorialização, na experiência do imprevisto e do trânsito, o que ainda parece ser um dos grandes problemas da sociedade contemporânea, temerosa de se perder nos labirintos das cineses que ela própria produz. É um grande paradoxo pensar em atenção à saúde mental de errantes por modelos de assistência que propõem ações e serviços cravados em bases territoriais e que visam promover a reintegração social do sujeito por meio de produção de vínculos sociais e afetivos sedimentários.

\section{Considerações finais}

Por que a errância e a loucura causam tanto desconforto, sendo, ambas, tão cingidas no ser humano e importantes para a construção da mundanalidade? Afinal a "pulsão de errância", que podemos considerá-la como errância geográfica, social, cultural e psicológica, não teria sido a responsável pelo homem ter buscado alternativas várias de vida em habitats distintos, por todo o planeta; por ele ter buscado outras alternativas para pensar, simbolizar e se relacionar com os outros, com isso, ter conseguido criar uma grande diversidade de sociedades, culturas e de 
subjetividades que lhe deram condições de expandir as possibilidades da vida? A errância, no fundo, tem um caráter de ampliação dos vínculos e das relações capaz de retirar o sujeito de círculos fechados e colocá-lo em conexão com realidades e subjetividades distantes; lança-o rumo ao novo e ao desconhecido. Analogamente, poderíamos entender a loucura como imbuída também desse componente errático e desviante que lança o sujeito para fora dos sulcos sociais e psicológicos que conduzem os desejos e pautas de conduta rumo a uma mesma direção, estabelecendo a normalidade.

No entanto, mesmo depois de um longo processo civilizatório, com a incessante produção de explicações causalistas, com a produção de modos amplos de intervenção, de criação de sofisticados procedimentos de controle, avaliação e classificação, promovidos pelas ciências biomédicas e humanas, tudo isso amparado e legitimado pelo poder do conhecimento científico, a errância e a loucura, ainda mais quando são vistas juntas, geram um demasiado estranhamento e suscitam as clássicas atitudes de confinamento e controle, inclusive entre profissionais que criticam a institucionalização.

Além de estratégias de confinamento, outra bastante utilizada é a expulsão dos loucos e errantes, tal como ocorria em outros tempos quando aqueles considerados loucos e indesejados, tais como pobres e mendigos, eram colocados em embarcações precárias - chamadas de "Nau dos Loucos" - e enviados para outros lugares, ou simplesmente deixando que o curso do rio selasse seus destinos. Atualmente, ainda encontramos muitas naus de loucos e "naus de errantes" nos procedimentos adotados por alguns municípios, tais como a desova de "mendigos" em outras cidades utilizando-se veículos da administração pública ou, ainda, por uma estratégia mais sutil que consiste em dar passe de ônibus aos trecheiros, mas sempre com o mesmo intuito colocá-los em trânsito constante.

Institucionalização e trânsito permanente parecem ser contraditórios quando se trata da loucura e da errância, no entanto, são dois mecanismos muito eficazes e complementares, pois a conjugação da lógica da sociedade disciplinar com a lógica da sociedade de controle produz um entrelaçamento de estratégias e dispositivos que buscam capturar os indivíduos em todos os espaços para serem cuidados, via de regra, em situações de reclusão ou, no mínimo, em situações que o colocam em algum círculo bem delimitado.

Dessa forma, se produz um efeito bumerangue entre a institucionalização e espaços abertos, no qual os confinamentos são acionados para a contenção e docilização e os controles em espaços abertos são acionados para o monitoramento e rastreamento de mobilidades. As instituições tradicionais e outras recentes, porém produtoras de espaços fechados, são articuladas em rede, buscando-se modular a velocidade dos ritmos da vida, dos desejos e dos trajetos. No extremo, tais políticas consistem em fazer parar e fazer andar, sempre utilizando o estacionamento ou a mobilidade como instrumento de controle e de gestão da vida.

É preciso considerar que a lógica da Atenção Psicossocial não se desprende inteiramente de uma visão sedentarizadora, capaz de contemplar a loucura e o sofrimento psíquico na errância e no nomadismo. Suas estratégias e 
dispositivos ainda reproduzem uma lógica normalizadora regida pelas noções de território, grupo social e familiar. Nesse sentido, a Atenção Psicossocial necessita, também, construir estratégias e dispositivos diversos dos atuais para alcançar esse público, sem capturá-los e, o que é mais perturbador, sem instituir a lei da sobrevivência sedentária a qualquer custo. As políticas públicas se movimentam por esse paradoxo quando são dirigidas e acionadas para agir em relação a mobilidades tidas como contraproducentes, desviantes, produtoras de vulnerabilidades ou de vidas consideradas indignas, tal como são vistas muitas vidas profundamente marcadas pela errância. Sob o manto racionalizador de garantias de direitos, provimentos e assistências básicos, podem se desenvolver práticas de contenção, controle ou até de repressão de vidas consideradas perigosas porque são erráticas, fugidias e não aderentes às tentativas de gestão que procuram mantê-las ao alcance, ainda que por algum tênue fio de conexão, com mecanismos destinados a promover e assegurar a normalidade instituída.

Os casos dos trecheiros e andarilhos, como também das pessoas em situação de rua, expressa bem esse paradoxo da sociedade atual que, por um lado, estimula a celeridade, o trânsito, a volatilidade, a vida em movimento, mas, ao mesmo tempo, procura monitorar, controlar e direcionar os fluxos, selecionando, mantendo e impulsionando aqueles que correspondem aos interesses dominantes e procurando frear, erradicar ou paralisar aqueles que são considerados indesejáveis e contraproducentes.

Nesse sentido, faz-se necessário questionar as políticas dirigidas àqueles que não se enquadram nos padrões estabelecidos, como é o caso dos errantes. É necessário interrogar e examinar essas políticas em seus fundamentos, sobretudo no que diz respeito ao sedentarismo e nomadismo. Trata-se de saber se levam em conta ou admitem o nomadismo e errância como modo possível de vida, ou seja, se buscam garantir e fortalecer formas de vida errantes distantes da normalidade - que até podem soar como estranhas ou extravagantes - e não simplesmente tentar aproximá-las de modelos normativos ou assegurar uma vida mínima de sobreviventeszumbis, tal como aqueles judeus, vítimas das atrocidades dos campos de concentração dos nazistas (Agamben, 2008), que mal conseguiam ficar em pé e sequer conseguiam exibir algum outro sinal de vida, como um simples brilho no olhar. A Atenção Psicossocial não está imune a esses desafios e problemas, cabendo a nós escolher ou inventar formas de atenção e cuidado para os nômades e errantes que não os desqualifiquem ou desqualifiquem suas formas de viver, tornando-os meros sobreviventes.

\section{Referências}

Agamben, G. (2008). O que resta de Auschwitz: o arquivo e a testemunha (Homo Sacer III). Belo Horizonte: Editora UFMG.

Albuquerque, C. M. C. (2009). Loucos nas ruas: um estudo sobre o atendimento à população de rua adulta em sofrimento psíquico na cidade do Recife. Dissertação de mestrado, Universidade Federal do Pernambuco, Recife, Brasil.

Amarante, P. (1996). O homem e a serpente: outras histórias para a loucura e a Psiquiatria. Rio de Janeiro: Editora Fiocruz. 
Amarante, P. (2009, jan-abr). Reforma Psiquiátrica e Epistemologia.Cad. Bras. Saúde Mental, 1(1). Recuperado em 20 abril, 2017, de http://stat.necat.incubadora.ufsc.br/inde x.php/cbsm/article/viewFile/998/1107

Amarante, P. (2007). Saúde mental e atenção psicossocial. Rio de Janeiro: Editora Fiocruz.

Augé, M. (2012), Não lugares: introdução a uma Antropologia da supermodernidade. Campinas: Papirus.

Bardin, L. (2009). Análise de Conteído. Lisboa: Edições 70.

Bauman, Z. (1998). Mal-estar na pós-modernidade. Rio de Janeiro: Jorge Zahar Editor.

Borysow, C. B., \& Furtado, J. P. (2014). Acesso, equidade e coesão social: avaliação de estratégias intersetoriais para a população em situação de rua. Revista da Escola de Enfermagem da USP, 48(6), 1069-1076.

Brazão, J. C. C. (2014). Vínculo e afeto na atualidade: impactos do novo capitalismo. Revista Polis e Psique, 4(1), 90-109.

Brasil. (2012a) Ministério da Saúde: Secretaria de Gestão Estratégica e Participativa. Plano operativo para implementação de ações em saúde da população em situação de rua 2012-2015. Brasília: MS.

Brasil. (2012b). Ministério da Saúde. Secretaria de Atenção à Saúde. Departamento de atenção Básica. Normas e Manuais Técnicos. Manual sobre o cuidado à saúde junto à população em situação de rua. Brasília-DF: MS.

Brasil. República Federativa do Brasil. (2012c). Portaria n 122, de 25 de janeiro de 2012. Define as diretrizes de organização e funcionamento das Equipes de Consultório na Rua. Recuperado em 17 abril, 2017, de http://bvsms.saude.gov.br/bvs/saudelegi s/gm/2012/prt0122_25_01_2012.html

Brasil. (2012d). Ministério da Saúde. Política Nacional de Atenção Básica. Secretaria de Atenção à Saúde. Departamento de Atenção Básica. Brasília: Ministério da Saúde.

Brasil, República Federativa do Brasil. (2011). Portaria ñ 3.088, de 22 de dezembro de 2011. Institui a Rede de Atenção Psicossocial para pessoas com sofrimento ou transtorno mental e com necessidades decorrentes do uso de crack, álcool e outras drogas, no âmbito do Sistema Único de Saúde (SUS). Recuperado em 20 agosto, 2018, de http://bvsms.saude.gov.br/bvs/saudelegi s/gm/2011/prt3088_23_12_2011_rep.ht $\mathrm{ml}$

Brasil. (2010). Ministério da Saúde. SAS/Dapes. Coordenação Nacional de Saúde Mental/Convênio Escola Politécnica Joaquim Venâncio - Fiocruz. Consultórios de Rua do SUS. Material de trabalho para a II Oficina Nacional de Consultórios de Rua do SUS. Brasília.

Brasil. República Federativa do Brasil. (2008). Política Nacional para Inclusão da População em Situação de Rua. Brasília: Governo Federal. Costa, P. C. (2013, 11 de junho). Internação compulsória de moradores de rua. Jornal de Assis, 13, 3. 
Danziato, L. J. B. (2010). O dispositivo do gozo na sociedade do controle. Psicologia $e$ Sociedade, 22(3), 430-437.

Deleuze, G. (1992). Conversações. São Paulo: Editora 34.

Foucault, M. (2003). História da loucura na idade clássica. São Paulo: Perspectiva.

Foucault, M. (2009). Vigiar e punir: nascimento da prisão. Petrópolis: Vozes.

Foucault, M. (2010). Os anormais. São Paulo: Editora Martins Fontes.

Frangella, S. (2004). Corpos urbanos errantes: uma etnografia da corporalidade de moradores de rua em São Paulo. Tese de doutorado, DAIFCHUnicamp, Campinas.

Geremek, B. (1995). Os filhos de Caim: vagabundos e miseráveis na literatura européia (1400-1700). Cia das Letras.

Julião, A. (2013, setembro). Vidas errantes. Revista Unespciência, 5(45), 36-43.

Justo, J. S. (2011a). Saúde Mental em trânsito: loucura e a condição de itinerância na sociedade contemporânea. In M. L. Boarini (Org.). Desafios na atenção à saúde mental (pp. 203-234). Maringá: Eduem.

Justo, J. S. (2011b). Andarilhos e trecheiros: errância e nomadismo na contemporaneidade. Maringá: Eduem.

Justo, J. S. (2012). Vidas errantes: politicas de mobilidade e experiências de tempo-espaço. Londrina: Eduel.

Kasper, C. (2006). Habitar as ruas. Tese de doutorado, Instituto de Filosofia e Ciências Humanas, Universidade Estadual de Campinas.

Lancetti, A. (2008). Clínica peripatética. São Paulo: Hucitec.
Maffesoli, M. (2001). Sobre o nomadismo: vagabundagens pós-modernas. Rio de Janeiro: Record.

Nascimento, E. C. (2012). Errância no contemporâneo: um estudo sobre a percepscão de dirigentes e profissionais de instituições assistenciais em relação a andarilhos de estrada. Tese de doutorado, Faculdade de Ciências e Letras, Unesp, Campus de Assis, Assis, Brasil.

Nascimento, E. C., Justo, J. S. (2010). Vidas errantes e alcoolismo: uma questão social. Psicologia: Reflexão e Crítica, 13(3), 529-538.

Varanda, W. (2009). Liminaridade, bebidas alcoólicas e outras drogas: funções e significados entre moradores de rua. Tese de doutorado, Faculdade de Saúde Pública da Universidade de São Paulo, USP, São Paulo, Brasil.

Virilio, P. (1993). O espaço crítico. Rio de Janeiro: Editora 34.

Virilio, P. (1996). Velocidade e política. São Paulo: Editora Liberdade.

Yasui, S., Luzio, C. A., \& Amarante, P. (2018). Atenção psicossocial e atenção básica: a vida como ela é no território. Revista Polis e Psique, 8(1), 173-190.

Recebido em: 24/07/2017 Aprovado em: 26/03/2018 